DOI: 10.5604/01.3001.0012.8032

\title{
METHOD OF SAFE LANDING THE EMERGENCY QUADROCOPTER
}

\author{
Bohdan Blagitko, Yuriy Mochulsky \\ Ivan Franko Lviv's National University, Faculty Electronics and Informational Technology, Department Radiofhysics and Computer Technology
}

Abstract. By means of mathematical modelling, the main features of emergency landing of quadrocopter are determined. The results of simulate landings of the quadrocopter in cases of failure of one of four pairs of electric motor screw are given. The methods of safe landing of an unmanned quadrocopter in case of failure of one of four pairs of motor-screw are proposed. The basis of the proposed methods is to use a parachuting effect. Parachuting achieved by forced off the power of the motor, which is located at the opposite end of the same yoke as faulty motor. As a result, the vertical speed of the quadrocopter at the time of landing significantly decreases in comparison with the speed of free fall.

Keywords: quadrocopter, 3-axis gyroscope, 3-axis accelerometer, 3-axis magnetometer

\section{METODA BEZPIECZNEGO LADDOWANIA AWARYJNEGO KWADROKOPTERA}

Streszczenie. Podstawowe cechy awaryjnego ladowania bezzałogowego kwadrokoptera zostaty opisane metodami modelowania matematycznego. Zaproponowano metode bezpiecznego ladowania bezzałogowego kwadrokoptera $w$ przypadku awarii jednego z czterech par silnik-wirnik. Podstawa proponowanej metody jest zastosowanie efektu spadochronu. Efekt spadochronujest osiagany poprzez przymusowe wylaczenia zasilania silnika elektrycznego, który znajduje się na przeciwległym końcu belki z uszkodzonym silnikiem. W rezultacie prędkość pionowa kwadrokoptera w momencie lądowania znaczaco maleje w stosunku do prędkości swobodnego spadania.

Slowa kluczowe: kwadrokopter, żyroskop 3-osiowy, 3-osiowy akcelerometr, 3-osiowy magnetometr

\section{Introduction}

In most articles on the problems of the quadrocopter flight, it is implicitly assumed that all four pairs of motor-screw and their control circuit are serviceable [5, 6, 8, 9]. In practice, often there are those or other faults in the sequence of links: the control circuit - the motor-screw. When a malfunction suddenly appears during the quadrocopter flight, then an emergency situation occurs.

In this article through mathematical modeling the basic features of quadrocopter emergency landings are considered. The results of mathematical modelling of quadrocopter emergency landings after the appearance of failure of one of the four electric motor-screws are presented.

\section{Simulation of the quadrocopter landings in the event of the failure of one of the four electric motor-screw}

The volume of the whole article should include an even number of pages. The last page should be filled at least $50 \%$. The author should make efforts to fill a total volume of pages with formatted article. We propose to write the text directly on this template, it will help you to meet the editorial requirements. Please do not break the text - do not use non-breaking spaces, hard (manual) line breaks, etc. The Editor reserves the right to editorial redaction of the submitted texts.

\section{Equations}

The mathematical model of a quadrocopter in flight in the event that all four pairs of the electric motor screw and the control scheme of them are regular are considered as two essentially different mathematical models. Actually the mathematical model of the quadrocopter is the UAV the inputs of which are the values of the voltage supply of electric motors, and the outputs are the altitude and angles of the roll, pitch and yaw. The mathematical model of the PD regulator is a system in which inputs a measured value from the sensors of height, the angles of the pith, the roll and the yaw, and the microcontroller implements the PD algorithm and outputs the voltage values of the electric motors. The mathematical model of the quadrocopter in flight in the event that all four pairs of electric motor screw and the control scheme are useful, is described by the system of differential equations of the 16th order in the form of Cauchy [6].

In case of failure of one of the four pairs of electro-motorscrew quadrocopter, the following cases are possible: failure of the nasal steam motor-screw; failure of the tail-pair motor-screw: failure of the right pair of electric motor-screw; failure of the left pair motor-screw. The simulating of malfunctioning was performed by switching off the power of the faulty motor.

In order to solve the differential equations of the mathematical model of the quadrocopter, the implicit Runge-Kutta method TR-BDF2 was used (in the first stage of the equation integrated by the trapezium formula method, and in the second stage of the second order (differentiation formula back is used)).

The landing of the quadrocopter occurs after it has been suspended at a height of $50 \mathrm{~m}$ above the point with coordinates $\mathrm{X}=0, \mathrm{Y}=0$. The quadrocopter "nose" leads in the direction plus by axis $\mathrm{X}$. In this case, the initial values of the angles of the pitch and the roll are zero, and the angle of yaw is $90^{\circ}$. Simulation of the failure of a specific pair of electric motor screw is carried out by assigning the supply voltage of the corresponding motor to a value of $0.0 \mathrm{~V}$ for all moments of time $\mathbf{t}=>\mathbf{t a}$, where ta is the moment of failure of a specific pair of the electric motor-screw of the quadrocopter.

In all articles [5, 6, 8, 9] about the simulations, the quadrocopter motions are considered as movements of the material point of a mass $\mathrm{m}$. But the quadrocopter has a complex spatial structure with certain dimensions. In order to see not only the movement of the center of the masses of the quadrocopter but also the idea of its rotation during an emergency landing, the movements of the two points of the quadrocopter, the center of mass and the nasal engine, were simulated. On Fig. 1 and on Fig. 4 the dashed line shows the trajectory of the center of the masses of the quadrocopter, and the squares of the trajectory of the movement of the nasal engine.

The results of mathematical modeling of the process of landing a quadrocopter in the event of a failure of one of the four pairs of the electric motor-screw of the quadrocopter are given in the form of a graph of trajectories of motion in Fig. 1. Trajectory 1 reflects the process of landing a quadrocopter in the failure of the nose pair of electric motor screw, and trajectory 3 - in the event of failure of the tail pair the motor-screw.

As can be seen from Fig. 2, after the accidental disconnection of the nasal electric motor, the pitch angle begins to decrease (the quadrocopter "lowers" the nose). As shown in [8], the nasal and tail motors create the momentum of the forces that the quadrocopter rotates in relation to the vertical axis clockwise (if viewed from the bottom). The right and left motors rotate the quadrocopter counter-clockwise relative to this axis. Therefore, when the nasal engine fails, the quadrocopter starts to rotate counter-clockwise. The Pitch and Yaw create a gyroscopic moment of forces, which begins to rotate the quadrocopter relative to the longitudinal axis, that is, there is a roll. Having made a little more than one turn relative to the transverse axis, the quadrocopter starts to rotate in the opposite direction, and in the future the Pitch 
ranges in the vicinity of $-150^{\circ}$. As for the longitudinal axis, the quadrocopter makes almost five turns in the negative direction and falls to the ground by the right engine.

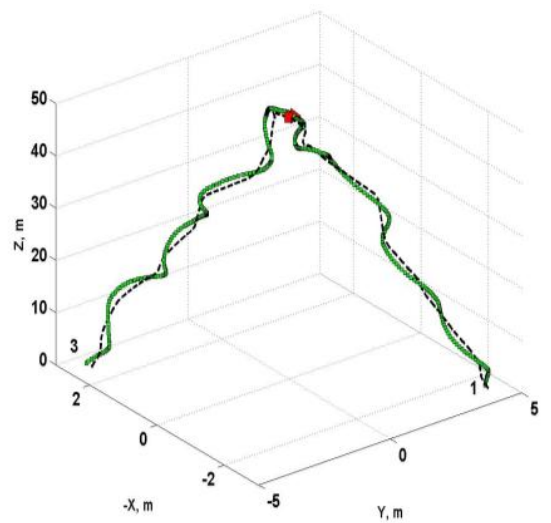

Fig. 1. Trajectories of the motion of the quadrocopter with the regulator: 1 -in case of failure of the nose pair motor-screw, 3 -in case of failure of the tail motor-screw

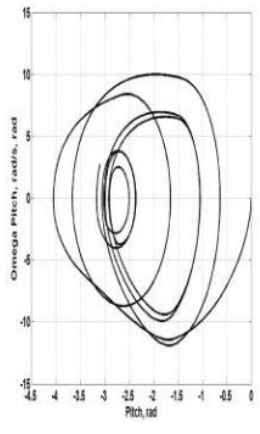

a) Pitch

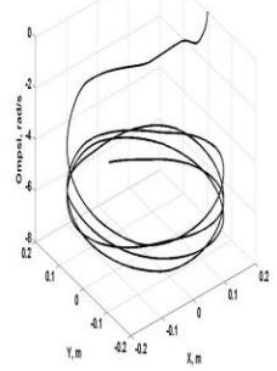

b) Yaw

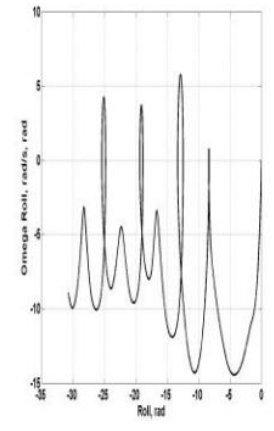

c) Roll
Fig. 2. Phase portraits of pitch, yaw and roll angles when the nose engine fails

Phase portraits of the angles of the Pitch, of the Yaw and of the Roll after having at the moment $\mathbf{t a}=1 \mathrm{~s}$ rejected the tail engine, drawn on Fig. 3.

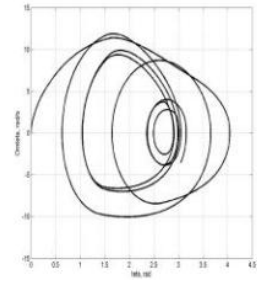

a) Pitch

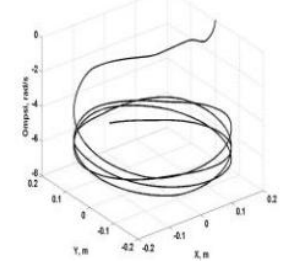

b) Yaw

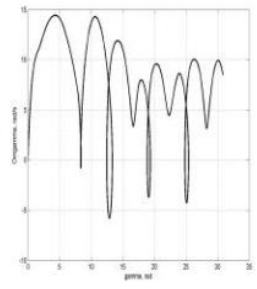

c) Roll
Fig. 3. Phase portraits of pitch, yaw and roll angles when the tail engine fails

As can be seen from Fig. 3, after the emergency shutdown of the tail motor, the pitch angle begins to increase (quadrocopter "lowers" the tail). As indicated above, the nasal and tail motors rotate the quadrocopter relative to the vertical axis in the same direction. But the angular Pitch speed changed the direction of rotation to the opposite. Therefore, the gyroscopic moment of forces causes the quadrocopter's Roll in the opposite direction. By making more than one turn in a positive direction relative to the transverse axis, the quadrocopter starts to rotate in the opposite direction, and in the future the pitch fluctuates in the vicinity of $+150^{\circ}$. With regard to the longitudinal axis, the quadrocopter makes almost five turns in a positive direction and falls to the ground on the left engine.

The results of mathematical modelling of the process of landing of the quadrocopter in the event of failure of one of the other pairs of the electric motor-screw quadrocopter are given in the form of a graph of trajectories of motion in Fig. 4. Trajectory 2 reflects the process of landing the quadrocopter with the failure of the right pair motor-screw, and trajectory 4 - in the case of failure of the left pair motor-screw.

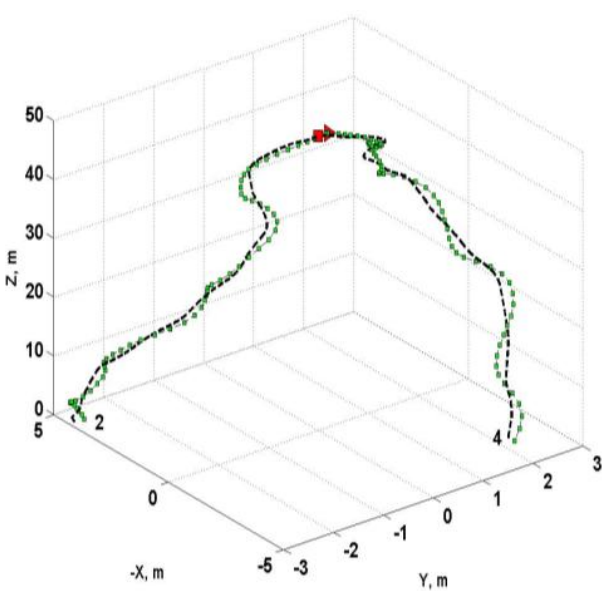

Fig. 4. Trajectories of the motion of the quadrocopter with the regulator: 2 -in case of failure of the right pair of electric motor-screw, 4 -in the failure of the left pair motor-screw

Phase portraits of the angles of the Roll, of the Yaw and of the Pitch after having at the moment $\mathbf{t a}=1 \mathrm{~s}$ rejected the right engine are shown in Fig. 5.

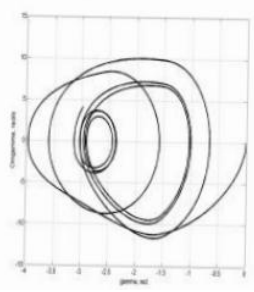

a) Pitch

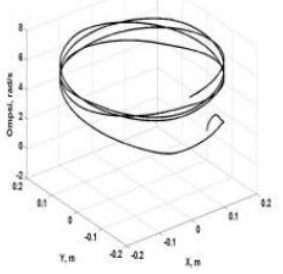

b) Yaw

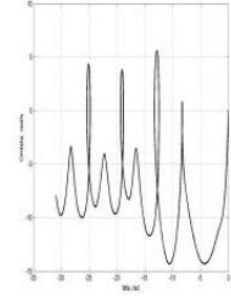

c) Rol
Fig. 5. Phase portraits of roll, yaw and pitch angles when the right engine fails

As can be seen from Fig. 5, after the trip of the right electric motor, the angle of the roll begins to increase (the quadrocopter "drops" to the right). The right and left engines create moment of forces, which rotates the quadrocopter relative to the vertical axis counterclockwise (if you look from below). Therefore, when the right engine fails, the quadrocopter starts to rotate clockwise. The Roll and Yaw create a gyroscopic moment of forces, which begins to rotate the quadrocopter relative to the transverse axis, that is, there is a pitch. Having made a little more than one turn relative to the longitudinal axis, the quadrocopter begins to rotate in the opposite direction, and in the future the roll varies in the vicinity of $+150^{\circ}$. As for the transverse axis, the quadrocopter makes almost five turns in a positive direction and falls to the ground on the nasal motor.

Phase portraits for changing the angles of the roll, yaw and pitch after having turned off the left engine at the time ta $=1 \mathrm{~s}$, are shown in Fig. 6 .

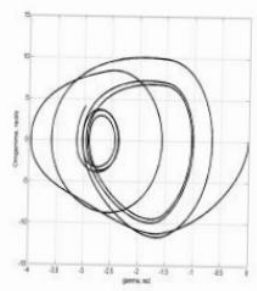

a) Pitch

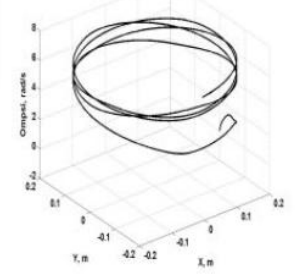

b) Yaw

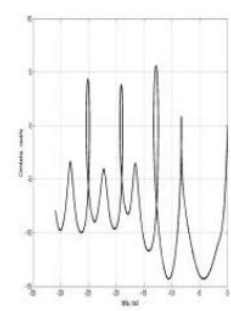

c) Roll
Fig. 6. Phase portraits of roll, yaw and pitch angles when the left engine fails

As can be seen from Fig. 6, after the emergency cut-off of the left electric motor, the angle of the roll begins to decrease (the quad-compressor "falls" to the left). At the same time, as a result of uncompensated moments of forces relative to the vertical axis, the quadrocopter starts to rotate clockwise. The gyroscopic moment of forces causes the quadrocopter Pitch. Having made a 
little more than one rotation relative to the longitudinal axis, the quadrocopter starts to rotate in the opposite direction, and in the future the roll varies in the vicinity of $-150^{\circ}$. As for the transverse axis, the quadrocopter makes almost five turns in the negative direction and falls to the ground on the tail engine.

It should be noted that the above-mentioned fall of the quadrocopter to the ground, when one of the engines fails, is valid only when a drop from a height of $50 \mathrm{~m}$ and zero initial angles of pitch and roll. Under other initial conditions, due to the rotation of the quadrocopter relative to all three axes, it is possible to fall to the ground in any position.

Emergency landing of a quadrocopter with failure of one of four pairs of electric motor-screw has significant disadvantages, namely: unpredictable landing point, unpredicted speed at the time of landing, unpredicted duration of fall and its nature, unpredicted landing angle, and the like.

\section{Method of safe landing of quadrocopter with failure of one of the pairs of electric motor-screw}

This article proposes a control method for the safe landing of a quadrocopter with a failure of one of the four pairs of electric motor-screw. The proposed method is to forcibly shut off the electric motor, which in paring with the already defective electric motor is located on the opposite end of the same console. This method uses the parachuting effect of the quadrocopter. Parachuting achieved by forced off the power of the motor, which is located at the opposite end of the same yoke as faulty motor As a result, the vertical speed of the quadrocopter at the time of landing significantly decreases in comparison with the speed of free fall.

For example, the simulation results of a safe landing of an emergency quadrocopter with a height of $50 \mathrm{~m}$ over a point with coordinates $X=0, Y=0$. Quadrocopter at the same time "hangs" motionless (the angles of the pitch and the roll are zero). The main parameters of the quadrocopter: mass - $468 \mathrm{~g}$, distance from the center of mass to the engine $-22.5 \mathrm{~cm}$, EMC battery $-11.1 \mathrm{~V}$.

Phase portraits of the angle of Yaw for the proposed method of safe emergency landing of the quadrocopter are shown in Fig. 7 (in the of the failure of the nose engine and the instantaneous disconnection case of the tail engine) and in Fig. 8 (in the case of failure of the left engine and instant disengagement of the right motor).

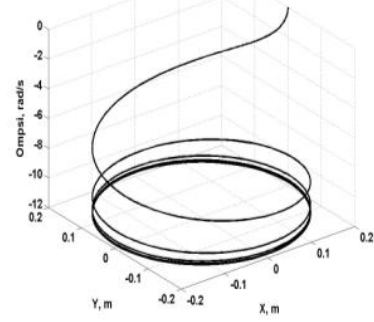

Fig. 7. Phase portrait of the angle of Yaw in the failure of the nose or tail engine

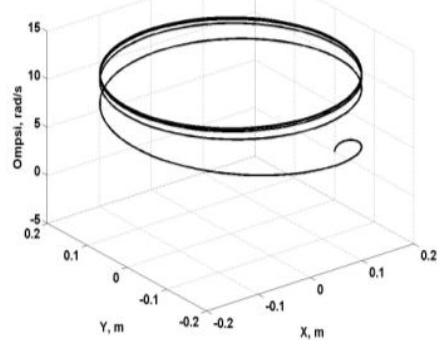

Fig. 8. Phase portrait of the angle Yaw at the failure of the right or left engine
Fig. 9 depicts a fragment of a safe emergency landing of a quadrocopter with a failure of the nasal engine and the instantaneous shutdown of the tail engine or with the cessation of the tail engine and the instantaneous disconnection of the nasal engine.

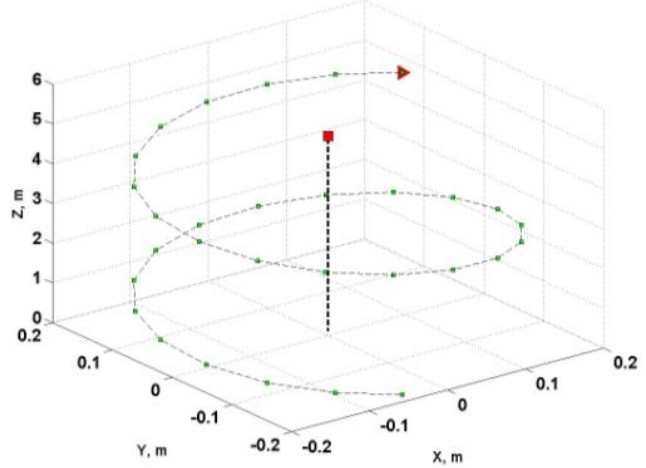

Fig. 9. Safe emergency landing of the quadrocopter at the failure of the nose or tail engine

Fig. 10 depicts a fragment of a safe emergency landing of a quadrocopter with a failure of the right engine and the instant disconnection of the left engine or the failure of the left engine and instant disabling of the right engine.

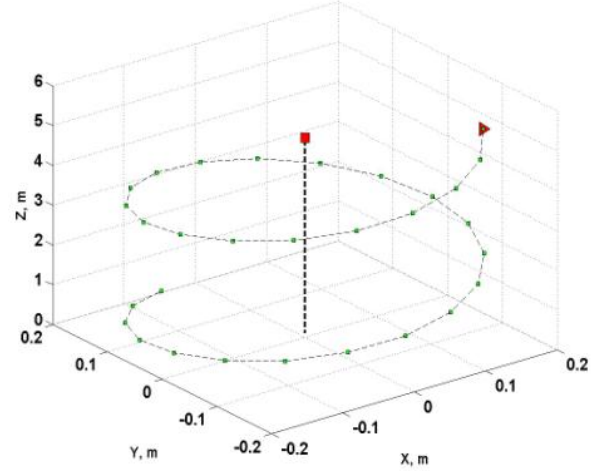

Fig. 10. Safe emergency landing of the quadrocopter with the failure of the left or right engine

For comparison: Fig.11 shows the process of landing a emergency quadrocopter in the event of a failure of one of the four pairs of motor-screw and the safe emergency landing of a quadrocopter with a failure of right engine and instantaneous shutdown of the left engine of a failure of left engine and instantaneous shutdown of the right engine.

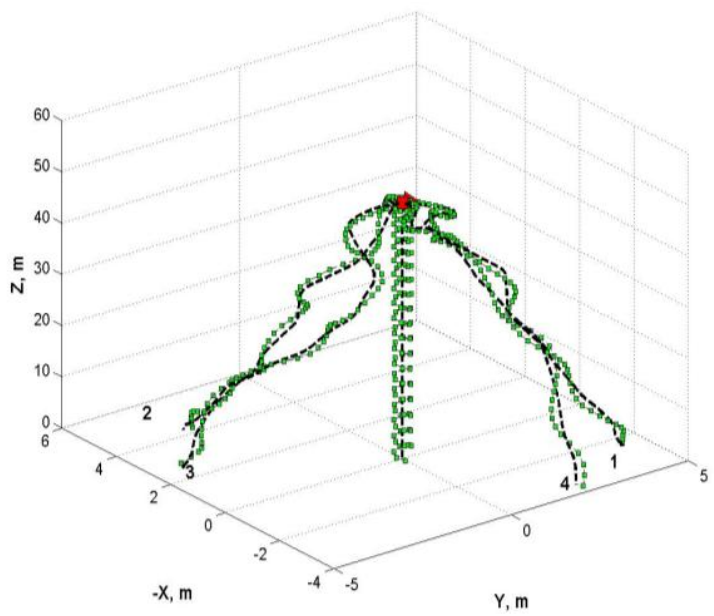

Fig. 11. Trajectories of the motion of the quadrocopter with the regulator: 1 -in case of failure of the nose pair motor-screw, 3 - in case of failure of the tail motor-screw, 2 - in case of failure of the right pair of electric motor-screw, 4 -in the failure of the left pair motor-screw, M-in case of safe emergency landing of the quadrocopter with the failure of the left or right engine 


\section{Discussion of the simulation results of the landing process of an emergency quadrocopter}

When free fall all four engines are off, the quadrocopter reaches the ground in just 6 seconds. The vertical component of the landing speed at the same time is $16.5 \mathrm{~m} / \mathrm{s}$. In case of refusal of one engine and working three remaining during the time of reduction, there are moments of forces concerning the axes of pitch, roll and yaw.

Table 1 shows the simulation results of the landing process of an emergency quadrocopter in case of failure of one of the four motor-screw pairs. Due to this, the rate of change does not change monotonously and the vertical component of the landing speed decreases to $12.7 \mathrm{~m} / \mathrm{s}$. The roll and pitch change randomly during a fall and at the time of landing they take on different values depending on the fault

Table 1. The simulation results of the landing process of an emergency quadrocopter in case of failure of one of the four motor-screw pairs

\begin{tabular}{|c|c|c|c|c|c|c|}
\hline $\begin{array}{c}\text { Engine } \\
\text { failure }\end{array}$ & Pitch & Roll & Yaw & $\begin{array}{c}\mathrm{V}_{\mathrm{x}}, \\
\mathrm{m} / \mathrm{s}\end{array}$ & $\begin{array}{c}\mathrm{V}_{\mathrm{y},} \\
\mathrm{m} / \mathrm{s}\end{array}$ & $\begin{array}{c}\mathrm{V}_{\mathrm{z}} \\
\mathrm{m} / \mathrm{s}\end{array}$ \\
\hline nasal motor & $180^{\circ}$ & $40^{\circ}$ & $10^{\circ}$ & 0 & 1.47 & -12.7 \\
\hline right motor & $-47^{\circ}$ & $180^{\circ}$ & $160^{\circ}$ & -1.05 & 0.59 & -12.7 \\
\hline tail motor & $180^{\circ}$ & $-33^{\circ}$ & $5^{\circ}$ & 0.03 & -1.44 & -12.7 \\
\hline left motor & $28^{\circ}$ & $-170^{\circ}$ & $-180^{\circ}$ & 1.1 & -0.6 & -12.7 \\
\hline
\end{tabular}

In the event of a faulty nasal or tail motor, the quadrocopter falls to the landing site with screws down (pitch $=180^{\circ}$ ) and with a roll of $40^{\circ}$ and $-33^{\circ}$, respectively. Non-zero values of the horizontal velocity component at the moment of landing are an additional danger $\mathrm{V}_{\mathrm{y}}=1.47 \mathrm{~m} / \mathrm{s}$ and $\mathrm{V}_{\mathrm{y}}=-1.44 \mathrm{~m} / \mathrm{s}$, respectively. Depending on the friction coefficient at the landing site, the quadrocopter will still travel some distance along the ground.

In the event of a faulty right or left motor, the quadrocopter falls to the landing site with screws down $\left(\right.$ roll $=180^{\circ}$ ) and with a pitch of $-47^{\circ}$ and $28^{\circ}$, respectively. Non-zero values of the horizontal velocity component at the moment of landing are an additional danger $\quad \mathrm{V}_{\mathrm{x}}=-1.05 \mathrm{~m} / \mathrm{s}, \quad \mathrm{V}_{\mathrm{v}}=0.59 \mathrm{~m} / \mathrm{s}$ and $\mathrm{V}_{\mathrm{x}}=1.1 \mathrm{~m} / \mathrm{s}, \mathrm{V}_{\mathrm{y}}=-0.6 \mathrm{~m} / \mathrm{s}$, respectively. Depending on the friction coefficient at the landing site, the quadrocopter will still travel some distance along the ground.

Table 2 shows the simulation results of the landing process of an emergency quadrocopter in case of failure of one of the four motor-screw pairs and simultaneously with the engine that is out of order, turn off the power of the electric motor, which is located at the opposite end of the same traverse as the defective electric motor.

Table 2. The simulation results of the landing process of an emergency quadrocopte in case of failure of one of the four motor-screw pairs and simultaneously with the engine that is out of order, turn off the power of the electric motor which is located at the opposite end of the same traverse as the defective electric motor

\begin{tabular}{|c|c|c|c|c|c|c|}
\hline $\begin{array}{c}\text { Engine } \\
\text { failure }\end{array}$ & Pitch & Roll & Yaw & $\begin{array}{c}\mathrm{V}_{\mathrm{x}}, \\
\mathrm{m} / \mathrm{s}\end{array}$ & $\begin{array}{c}\mathrm{V}_{\mathrm{y}}, \\
\mathrm{m} / \mathrm{s}\end{array}$ & $\begin{array}{c}\mathrm{V}_{\mathrm{z}}, \\
\mathrm{m} / \mathrm{s}\end{array}$ \\
\hline nasal motor & $0^{\circ}$ & $0^{\circ}$ & $175^{\circ}$ & 0 & 0 & -5.6 \\
\hline right motor & $0^{\circ}$ & $0^{\circ}$ & $5^{\circ}$ & 0 & 0 & -5.6 \\
\hline tail motor & $0^{\circ}$ & $0^{\circ}$ & $175^{\circ}$ & 0 & 0 & -5.6 \\
\hline left motor & $0^{\circ}$ & $0^{\circ}$ & $5^{\circ}$ & 0 & 0 & -5.6 \\
\hline
\end{tabular}

If simultaneously with the engine that is out of order, turn off the power of the electric motor, which is located at the opposite end of the same traverse as the defective electric motor, then the time of fall is $11.7 \mathrm{~s}$, and the vertical landing speed is $5.6 \mathrm{~m} / \mathrm{s}$. The horizontal components of the speed all the time will be zero, that is, the quadrocopter will fall vertically down. The roll and pitch during the fall are zero, that is, the quadrocopter will always land on the chassis. Due to the fact that in this case, not compensated moments of the forces of two opposite engines, the speed of rotation around the vertical axis at the time of landing will be $4.4 \mathrm{rad} / \mathrm{s}$. This speed will create a distance of $22.5 \mathrm{~cm}$ from the center of mass of the acceleration $4.4 \mathrm{~m} / \mathrm{s}^{2}$.

\section{Conclusion}

The results of the conducted research determine the effectiveness and practical significance of the use of the proposed methods of safe landing of the quadrocopter, which in the flight unexpectedly refused one of the four pairs of propeller. To reduce the vertical component of the landing speed when the failure of one of the engines it is expedient as soon as possible to disconnect the voltage from the opposite engine, which is located on the opposite end of the console. In this case, the horizontal components of the speed are practically zero.

\section{References}

[1] Blagitko B., Mochulsky Y.: Emergency landing of quadrocopter in unmanned flight. Electronics and Information Technologies 8/2017, 137-142.

[2] Blagitko B., Mochulsky Y.: Mathematical modeling of quadrocopter stabilization in flight. Electronics and Information Technologies 3/2013, 96-107.

[3] Blagitko B., Zaiachuk I., Kit L., Mochulsky Y.: Modeling of the process of control of vertical take-off and landing of unmanned quadrocopter. Physicalmathematical modeling and information technologies 2/2012, 111-117.

[4] Blagitko B., Zaiachuk I., Mochulsky Y.: Mathematical modeling of the effect of sensor features on the flight process of an unmanned quadrocopter. Physical-mathematical modeling and information technologies 21/2015, 22-29.

[5] Huang H., Hoffmann G. M., Waslander S. L., Tomlin C. J.: Aerodynamics and control of autonomous quadrotor helicopters in aggressive maneuvering. IEEE International Conference on Robotics and Automation, May 2009, 3277-3282.

[6] Marcelo B.,.Sampaio R.C.B, Bounabdallah S., Perrot V., Siegwart R.: In-Flight Collision Avoidance Controller Based Only on OS4 Embedded Sensors. Journal of the Brazilian Society of Mechanical Sciences and Engineering XXXIV(3)/2012, 294-107.

[7] Mochulsky Y.: Matlab In Physical Research: tutor. - method. manual. VTS LNU them. Ivan Franko, Lviv 2004.

[8] Nartin P., Salaun E.: The True Role of Accelerometer Feedback in Quadrotor Control. IEEE International Conference on Robotics and Automation, Anchorage, May 2010, 1623-1629.

[9] Wissiere D., Bristeau P.-J., Martin A., Petit N.: Experimental autonomous flight of a small-scaled helicopter using accurate dynamics model and low-cost sensors. Proceeding of the 17th Word Congress The International Federation of Automatic Control. Seoul Korea 2008, 14642-14650.

\section{Ph.D. Blagitko Bohdan}

e-mail: blagitko@gmail.com

Associate-Professor of the Department Radiophysic and Computer Technology, Faculty Electronics and Informational Technology, Ivan Franko Lviv's National University.

His research and teaching interests are in areas microprocessor technique and systems, mainly concerned with mathematical modelling and simulation of processes in control dynamic systems, and computer-aided system analysis and design.

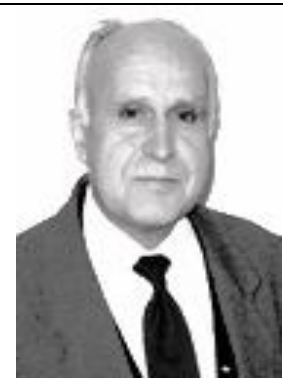

ORCID ID: 0000-0002-0516-9353

\section{Ph.D. Mochulsky Yuriy}

e-mail: mochulsky@ukr.net

Associate-Professor of the Department Radiophysics and Computer Technology, Faculty Electronics an Informational Technology, Ivan Franko Lviv's National University.

His scientific interests are mainly concerned with mathematical modelling and simulation of processe in dynamic radiophysical systems.

ORCID ID: 0000-0001-5488-4065

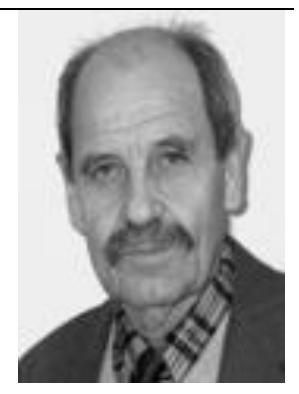

otrzymano/received: 1.10 .2018 przyjęto do druku/accepted: 15.12 .2018 